\title{
Acid-Sensing lon Channel 1 Contributes to Weak Acid-Induced Migration of Human Malignant Glioma Cells
}

\author{
Sareena Shah ${ }^{1}$, Yuyang $\mathrm{Chu}^{2}$, Victoria Cegielski ${ }^{1}$ and Xiang-Ping Chu ${ }^{1 *}$ \\ ${ }^{1}$ Department of Biomedical Sciences, School of Medicine, University of Missouri-Kansas City, Kansas City, MO, \\ United States, ${ }^{2}$ Feinberg School of Medicine, Northwestern University, Chicago, IL, United States
}

Keywords: acid-sensing ion channel 1, human malignant glioma cells, migration, acidosis, patch-clamp recording

\section{INTRODUCTION}

Glioblastoma multiform (GBM), also referred to as glioblastoma, is the most common malignant tumor in the brain, known for its resistance to therapeutic agents and poor prognosis (Shergalis et al., 2018). Recent studies have seen success of some target compounds in combating GBMs in laboratory settings; however, these compounds failed in clinical trials (Mandel et al., 2018). Multiple factors may have contributed to this drug failure in GBM treatment, including difficulty

OPEN ACCESS

Edited by:

Osvaldo D. Uchitel,

University of Buenos Aires, Argentina

Reviewed by:

Mingli Liu,

Morehouse School of Medicine,

United States

*Correspondence: Xiang-Ping Chu chux@umkc.edu

Specialty section:

This article was submitted to Membrane Physiology and Membrane

Biophysics,

a section of the journal

Frontiers in Physiology

Received: 01 July 2021

Accepted: 16 August 2021

Published: 07 September 2021

Citation:

Shah S, Chu Y, Cegielski V and Chu X-P (2021) Acid-Sensing lon

Channel 1 Contributes to Weak

Acid-Induced Migration of Human

Malignant Glioma Cells.

Front. Physiol. 12:734418.

doi: 10.3389/fphys.2021.734418 penetrating the blood-brain barrier (BBB), an immunosuppressive microenvironment, and complex intratumoral heterogeneity (Khaddour et al., 2020; Ou et al., 2020). Difficulty in treating GBMs has led to a 5-year survival rate of $<7.2 \%$ in humans. This is the lowest long-term rate of malignant brain tumors (Ostrom et al., 2020). Current treatment options for patients with GBM include surgical resection and a combination of chemotherapy, radiotherapy, and immunotherapy (Carlsson et al., 2014; Suter et al., 2020; Wen et al., 2020; Medikonda et al., 2021). Surgical resection is the most effective way to increase short-term survival rate, with research demonstrating a higher 1 -year survival rate in patients with at least a $90 \%$ surgical resection compared to those without one (Medikonda et al., 2021). Yet, the long-term survival rate remains the same, suggesting that tumor recurrence is very likely (Yu et al., 2021).

GBMs, like many other tumors, have an acidic microenvironment due to the tumor's high rate of metabolism and limited blood supply (Tian et al., 2017). Acidosis may result from an accumulation of acid or an increase of partial pressure of carbon dioxide in tissues, which can cause lactic acid build-up in the brain (Chesler, 2003). Excessive lactic acid in the brain can damage metabolic functionality, hindering recirculation and reoxygenation throughout the body (Siesjö, 1982; Siesj et al., 1993; Rehncrona, 2005). Studies have demonstrated that acidosis can activate a family of ligand-gated ion channels: acid-sensing ion channels (ASICs), which are widely expressed in neurons (Waldmann et al., 1997; Xiong et al., 2004; Krishtal, 2015). ASICs are formed through different combinations of subunits, either homotrimeric or heterotrimeric, constituting different electrophysiological and pharmacological properties (Gründer and Pusch, 2015; Vullo and Kellenberger, 2020). The activation of ASICs induces neuronal depolarization and generates action potentials mostly due to the influx of $\mathrm{Na}^{+}$ions (Jiang et al., 2009; Boscardin et al., 2016). ASICs play critical roles in several physiological processes including synaptic plasticity, pain sensation, and fear conditioning (Wemmie et al., 2013; Huang et al., 2015; Uchitel et al., 2019; Storozhuka et al., 2021). They also contribute to several neurodegenerative disorders such as Parkinson's disease and multiple sclerosis (Chu and Xiong, 2012; Chu et al., 2014; Ortega-Ramírez et al., 2017). Additionally, ASICs are expressed in glial cells (Lin et al., 2010), particularly ASIC1, whose activation in glial cell lines has been linked to migration and proliferation of the GBMs 
(Berdiev et al., 2003; Bubien et al., 2004; Kapoor et al., 2009, 2011; Rooj et al., 2012). Glioma tumors aggressively destroy surrounding tissues while growing in the brain, displaying acidosis and resulting in pathophysiological consequences (Honasoge and Sontheimer, 2013). ASIC expression in glioma cells generates a $\mathrm{Na}^{+}$current which contributes to its volume and migration (Rooj et al., 2012). Active conductance has been observed in gliomas due to the presence of ASICs and epithelial sodium channels, which can impact cell cycle progression (Kapoor et al., 2009). The impact of ASICs, particularly ASIC1, in glial cell lines is being further investigated in efforts to reduce glial cell migration, study the potential proliferation effects, and to understand how ASIC1 inhibitors can regulate apoptosis of glioma cells (Sun et al., 2013; Tian et al., 2017). ASIC1 gene expression in glioma cells can predict outcomes of carcinomas as they act as genomic biomarkers; therefore, finding more inhibitors to ASICs may provide potential therapeutic agents to inhibit glioma cell activity (Sun et al., 2013; Bychkov et al., 2020; Griffin et al., 2020).

\section{ASIC1 CONTRIBUTES TO WEAK ACID-INDUCED MIGRATION OF HUMAN MALIGNANT CELLS}

A recent study from Dr. Xiong's laboratory published in the American Journal of Cancer Research described a combination of wet-lab techniques, including whole-cell patch-clamp recording, Western blotting, cell viability assay, wound-healing assay and trans-well migration assay, that were used to determine if the activation of ASIC1 by a weak acid (e.g., pH 7.0) had a correlation with the migration and proliferation of glial cell lines U87MG and A172 (Sheng et al., 2021). The study determined the expression of ASIC1 in glioblastoma cell lines, along with the induction of transient inward currents when the $\mathrm{pH}$ was dropped from 7.4 to 6.0, suggesting the existence of acid-activated currents in glioblastoma cell lines. When PcTx1, a selective ASIC1 inhibitor, was introduced, there was a decrease in acid-activated currents, indicating that ASIC1 was involved. The study also examined cell viability of A172 and U87MG cells when treated under different $\mathrm{pH}$ conditions (e.g., $\mathrm{pH} 7.4$ and $\mathrm{pH} \mathrm{7.0)}$ to determine if weak acidosis could affect proliferation of the cells; however, they found that neither acidosis nor the addition of PcTx1 had an influence on cell viability of the two glioma cells, suggesting that weak acidosis has no effect on proliferation of human glioma cells. Using a wound healing assay, they investigated whether weak acid could promote migration of A172 and U87MG cells and found that weak acid did increase the migration rate by $26 \%$ in A172 cells and 67\% in U87MG cells, respectively. When PcTx1 was introduced, it inhibited both glioma cells from migrating. Further investigation of this migration was conducted using a trans-well migration assay and revealed similar results. They also found that there was a heavier expression of the ASIC1 protein in U87MG cells compared to the expression in A172 cells, indicating that different cell lines of GBMs have different levels of ASIC1 expression. The study also introduced ASIC1-siRNA to U87MG cells, which silences ASIC1 expression, to better understand the influence of this protein on migration induced by treatment of weak acidosis. When compared to the control group, application of ASIC1-siRNA decreased the expression of the ASIC1 protein and did not affect the proliferation of U87MG cells, but it reduced the migration of U87MG cells under weak acidic conditions. Collectively, the results demonstrate that activation of ASIC1 by weak acidosis in glioma cells A172 and U87MG promotes migration of the cells but not proliferation, while PcTx1 inhibits migration of glioma cells. These findings suggest that ASIC1 could serve as a potential therapeutic target for GBMs.

\section{PERSPECTIVE}

Although there are several studies of ASICs in the pathophysiology of glioma cells (Berdiev et al., 2003; Bubien et al., 2004; Kapoor et al., 2009, 2011; Rooj et al., 2012), this study uniquely dives deeper into the connection between weak acidosis activated ASIC1 and its effect on the migration of glioma cells (Sheng et al., 2021). A recent study from Dr. Grunder's group reported that glioblastoma stem cell (GSC) lines (R8 and R54) express functional ASIC1 and ASIC3, and their data suggest that expression of ASICs is associated with an improved survival in GSC lines (Tian et al., 2017). This result is inconsistent with other studies (Kapoor et al., 2009; Sheng et al., 2021). One possibility might be due to different glioblastoma cell lines used in different studies, suggesting the complexity of GBM. Therefore, additional studies might be necessary to further delineate the precise role of ASIC1 in high-grade glioblastoma. This study solely focuses on glial cells U87MG and A172, so it would be beneficial to utilize the same wet-lab techniques for cultured human glioma cells directly from the patients and see if parallel correlations are found. It would also be interesting to test PcTx1 on cultured human glioma cells to see whether it has any effects on glioma growth during a small $\mathrm{pH}$ drop $(\mathrm{pH} 7.0)$. In most whole-cell recordings, ASICs deactivate fast in response to brief $\mathrm{pH}$ stimulation (Gründer and Pusch, 2015). Even a small decrease in $\mathrm{pH}$ leads to profound steady state desensitization of ASICs. Therefore, it is intriguing how migration of high-grade gliomas could be promoted via ASIC continuously subjected to a slightly acidic $\mathrm{pH}$, and the exact mechanism should be explored in the near future. Interestingly, a recent study demonstrates that the deactivation of ASICla is steeply dependent on the $\mathrm{pH}$, spanning nearly three orders of magnitude from extremely fast ( $<1 \mathrm{~ms}$ ) at $\mathrm{pH} 8.0$ to very slow (more than $300 \mathrm{~ms}$ ) at $\mathrm{pH}$ 7.0 (MacLean and Jayaraman, 2017). In addition, like most of ligand-gated ion channels, the desensitization of ASIC is also $\mathrm{pH}$-dependent, with much slower desensitization occurs in response to a smaller $\mathrm{pH}$ drop (e.g., to 7.0) than a bigger $\mathrm{pH}$ drop (e.g., to 6.0). Although the current amplitude might be small with a small pH drop (Sheng et al., 2021), the current may last for a long period of time. Another possibility is that, in intact cells where cellular components are not washed out like in whole-cell recordings, the kinetics of ASIC1a current could be completely different. Additionally, the study from Dr. Xiong's group (Sheng et al., 2021) focuses on glial cells U87MG and A172 being 
introduced to a weak acid, but it would be insightful to compare the migration of these glial cell lines when introduced to a larger pH drop (e.g., pH 6.0). Further investigation may determine the consequences of cell migration under permanent inhibition of ASIC1 in glioma cells. Several existing studies have used PcTx1 or Mambalgin-2 as an ASIC1 inhibitor (Kellenberger and Schild, 2015; Dibas et al., 2019). However, it is necessary to explore other therapeutic agents since PcTx1 and Mambalgin-2 cannot be used in clinical settings due to their inability to cross the BBB (Sun et al., 2013; Bychkov et al., 2020). Therefore, determining effective delivery pathways for ASIC1 inhibitors is needed for the clinical treatment of GBMs. From a more malignant standpoint, late-stage glioma cells express high levels of ASIC1a, which is not portrayed in normal astrocytes. Thus, learning more about how and why ASIC1 expression changes in higher-grade gliomas may be vital in determining optimal treatment plans for patients with gliomas (Sun et al., 2013; Wang et al., 2015).

\section{REFERENCES}

Berdiev, B. K., Xia, J., McLean, L. A., Markert, J. M., Gillespie, G. Y., Mapstone, T. B., et al. (2003). Acid-sensing ion channels in malignant gliomas. J. Biol. Chem. 278, 15023-15034. doi: 10.1074/jbc.M300991200

Boscardin, E., Alijevic, O., Hummler, E., Frateschi, S., and Kellenberger, S. (2016). The function and regulation of acid-sensing ion channels (ASICs) and the epithelial $\mathrm{Na}^{+}$channel (ENaC): IUPHAR Review 19. Br. J. Pharmacol. 173, 2671-2701. doi: 10.1111/bph.13533

Bubien, J. K., Ji, H. L., Gillespie, G. Y., Fuller, C. M., Markert, J. M., Mapstone, T. B., et al. (2004). Cation selectivity and inhibition of malignant glioma $\mathrm{Na}^{+}$ channels by Psalmotoxin 1. Am. J. Physiol,. Cell Physiol. 287, C1282-1291. doi: 10.1152/ajpcell.00077.2004

Bychkov, M., Shulepko, M., Osmakov, D., Andreev, Y., Sudarikova, A., Vasileva, V., et al. (2020). Mambalgin-2 induces cell cycle arrest and apoptosis in glioma cells via interaction with ASIC1a. Cancers 12:1837. doi: 10.3390/cancers12071837

Carlsson, S. K., Brothers, S. P., and Wahlestedt, C. (2014). Emerging treatment strategies for glioblastoma multiforme. EMBO Mol. Med. 6, 1359-1370. doi: $10.15252 / \mathrm{emmm} .201302627$

Chesler, M. (2003). Regulation and modulation of $\mathrm{pH}$ in the brain. Physiol. Rev. 83, 1183-1221. doi: 10.1152/physrev.00010.2003

Chu, X.-P., Grasing, K. A., and Wang, J. Q. (2014). Acid-sensing ion channels contribute to neurotoxicity. Transl. Stroke Res. 5, 69-78. doi: 10.1007/s12975-013-0305-y

Chu, X.-P., and Xiong, Z.-G. (2012). Physiological and pathological functions of acid-sensing ion channels in the central nervous system. Curr. Drug Targets. 13, 263-271. doi: 10.2174/138945012799201685

Dibas, J., Al-Saad, H., and Dibas, A. (2019). Basics on the use of acid-sensing ion channels' inhibitors as therapeutics. Neural Regen. Res. 14, 395-398. doi: 10.4103/1673-5374.245466

Griffin, M., Khan, R., Basu, S., and Smith, S. (2020). Ion channels as therapeutic targets in high grade gliomas. Cancers 12:3068. doi: 10.3390/cancers12103068

Gründer, S., and Pusch, M. (2015). Biophysical properties of acidsensing ion channels (ASICs). Neuropharmacology 94, 9-18. doi: 10.1016/j.neuropharm.2014.12.016

Honasoge, A., and Sontheimer, H. (2013). Involvement of tumor acidification in brain cancer pathophysiology. Front. Physiol. 4:316. doi: 10.3389/fphys.2013.00316

Huang, Y., Jiang, N., Ji, Y., Xiong, Z., and Zha, X. (2015). Two aspects of ASIC function: synaptic plasticity and neuronal injury. Neuropharmacology 94 , 42-48. doi: 10.1016/j.neuropharm.2014.12.010

Jiang, Q., Li, M. H., Papasian, C. J., Branigan, D., Xiong, Z. G., Wang, J. Q., et al. (2009). Characterization of acid-sensing ion channels in

\section{AUTHOR CONTRIBUTIONS}

All authors listed have made a substantial, direct and intellectual contribution to the work and approved it for publication.

\section{FUNDING}

The work was supported by grant from American Heart Association (19AIREA34470007) to X-PC.

\section{ACKNOWLEDGMENTS}

We thank Dr. Zhi-Gang Xiong from Morehouse School of Medicine for his critical reading of this manuscript.

medium spiny neurons of mouse striatum. Neuroscience 162, 55-66. doi: 10.1016/j.neuroscience.2009.04.029

Kapoor, N., Bartoszewski, R., Qadri, Y. J., Bebok, Z., Bubien, J. K., Fuller, C. M., et al. (2009). Knockdown of ASIC1 and epithelial sodium channel subunits inhibits glioblastoma whole cell current and cell migration. J. Biol. Chem. 284, 24526-24541. doi: 10.1074/jbc.M109.037390

Kapoor, N., Lee, W., Clark, E., Bartoszewski, R., McNicholas, C. M., Latham, C. B., et al. (2011). Interaction of ASIC1 and ENaC subunits in human glioma cells and rat astrocytes. Am. J. Physiol,. Cell Physiol. 300, C1246-1259. doi: 10.1152/ajpcell.00199.2010

Kellenberger, S., and Schild, L. (2015). International union of basic and clinical pharmacology. XCI. structure, function, and pharmacology of acid-sensing ion channels and the epithelial $\mathrm{Na}+$ channel. Pharmacol. Rev. 67, 1-35. doi: 10.1124/pr.114.009225

Khaddour, K., Johanns, T. M., and Ansstas, G. (2020). The landscape of novel therapeutics and challenges in glioblastoma multiforme: contemporary state and future directions. Pharmaceuticals 13:389. doi: 10.3390/ph13110389

Krishtal, O. (2015). Receptor for protons: First observations on acid sensing ion channels. Neuropharmacology 94, 4-8. doi: 10.1016/j.neuropharm.2014.12.014

Lin, Y. C., Liu, Y. C., Huang, Y. Y., and Lien, C. C. (2010). High-density expression of $\mathrm{Ca}^{2+}$-permeable ASIC1a channels in NG2 glia of rat hippocampus. PLoS ONE 5:e12665. doi: 10.1371/journal.pone.0012665

MacLean, D. M., and Jayaraman, V. (2017). Deactivation kinetics of acid-sensing ion channel 1a are strongly $\mathrm{pH}$-sensitive. Proc. Natl. Acad. Sci. USA. 114, E2504-E2513. doi: 10.1073/pnas.1620508114

Mandel, J. J., Youssef, M., Ludmir, E., Yust-Katz, S., Patel, A. J., and De Groot, J. F. (2018). Highlighting the need for reliable clinical trials in glioblastoma. Expert Rev. Anticancer Ther. 18, 1031-1040. doi: 10.1080/14737140.2018.1496824

Medikonda, R., Dunn, G., Rahman, M., Fecci, P., and Lim, M. (2021). A review of glioblastoma immunotherapy. J. Neurooncol. 151, 41-53. doi: 10.1007/s11060-020-03 448-1

Ortega-Ramírez, A., Vega, R., and Soto, E. (2017). Acid-sensing ion channels as potential therapeutic targets in neurodegeneration and neuroinflammation. Mediators Inflamm. 2017:3728096. doi: 10.1155/2017/3728096

Ostrom, Q. T., Patil, N., Cioffi, G., Waite, K., Kruchko, C., and Barnholtz-Sloan, J. S. (2020). CBTRUS statistical report: primary brain and other central nervous system tumors diagnosed in the United States in 2013-2017. Neuro Oncol. 22, iv1-iv96. doi: 10.1093/neuonc/noaa200

Ou, A., Yung, W. K. A., and Majd, N. (2020). Molecular mechanisms of treatment resistance in glioblastoma. Int. J. Mol. Sci. 22:351. doi: 10.3390/ijms22010351

Rehncrona, S. (2005). Brain acidosis. Ann. Emerg. Med. 14, 770-776. doi: 10.1016/S0196-0644(85)80055-X 
Rooj, A. K., McNicholas, C. M., Bartoszewski, R., Bebok, Z., Benos, D. J., and Fuller, C. M. (2012). Glioma-specific cation conductance regulates migration and cell cycle progression. J. Biol. Chem. 287, 4053-4065. doi: 10.1074/jbc.M111.311688

Sheng, Y., Wu, B., Leng, T., Zhu, L., and Xiong, Z. (2021). Acid-sensing ion channel 1 (ASIC1) mediates weak acid-induced migration of human malignant glioma cells. Am. J. Cancer Res. 11, 997-1008.

Shergalis, A., Bankhead, A. I. I. I., Luesakul, U., Muangsin, N., and Neamati, N. (2018). Current challenges and opportunities in treating glioblastoma. Pharmacol. Rev. 70, 412-445. doi: 10.1124/pr.117.014944

Siesj,ö, B. K., Katsura, K., Mellergård, P., Ekholm, A., Lundgren, J., and Smith, M. L. (1993). Acidosis-related brain damage. Prog. Brain Res. 96, 23-48. doi: 10.1016/S0079-6123(08)63257-4

Siesjö, B. K. (1982). Lactic acidosis in the brain: occurrence, triggering mechanisms and pathophysiological importance. Ciba Found. Symp.87, 77-100. doi: 10.1002/9780470720691.ch5

Storozhuka, M., Cherninskyia, A., Maximyuka, O., Isaeva, D., and Krishtala, O. (2021). Acid-sensing ion channels: focus on physiological and some pathological roles in the brain. Curr. Neuropharmacol. doi: 10.2174/1570159X19666210125151824. [Epub ahead of print].

Sun, X., Zhao, D., Li, Y., Sun, Y., Lei, X., Zhang, J., et al. (2013). Regulation of ASIC1 by $\mathrm{Ca}^{2+} /$ calmodulin-dependent protein kinase II in human glioblastoma multiforme. Oncol. Rep. 30, 2852-2858. doi: 10.3892/or.2013.2777

Suter, R. K., Rodriguez-Blanco, J., and Ayad, N. G. (2020). Epigenetic pathways and plasticity in brain tumors. Neurobiol. Dis.145:105060. doi: 10.1016/j.nbd.2020.105060

Tian, Y., Bresenitz, P., Reska, A., Moussaoui, L. E., Beier, C. P., and Gründer, S. (2017). Glioblastoma cancer stem cell lines express functional acid sensing ion channels ASIC1a and ASIC3. Sci. Rep. 7:13674. doi: 10.1038/s41598-017-13666-9

Uchitel, O. D., González Inchauspe, C., and Weissmann, C. (2019). Synaptic signals mediated by protons and acid-sensing ion channels. Synapse 73:e22120. doi: $10.1002 /$ syn.22120

Vullo, S., and Kellenberger, S. (2020). A molecular view of the function and pharmacology of acid-sensing ion channels. Pharmacol. Res. 154:104166. doi: $10.1016 /$ j.phrs.2019.02.005

Waldmann, R., Champigny, G., Bassilana, F., Heurteaux, C., and Lazdunski, M. (1997). A proton-gated cation channel involved in acid-sensing. Nature 386, 173-177. doi: $10.1038 / 386173 \mathrm{a} 0$
Wang, R., Gurguis, C., Gu, W., Ko, E. A., Lim, I., Bang, H., et al. (2015). Ion channel gene expression predicts survival in glioma patients. Sci. Rep. 5:11593. doi: 10.1038/srep1 1593

Wemmie, J. A., Taugher, R. J., and Kreple, C. J. (2013). Acid-sensing ion channels in pain and disease. Nat. Rev. Neurosci. 14, 461-471. doi: 10.1038/nrn 3529

Wen, P. Y., Weller, M., Lee, E. Q., Alexander, B. M., Barnholtz-Sloan, J. S., Barthel, F. P., et al. (2020). Glioblastoma in adults: a Society for Neuro-Oncology (SNO) and European Society of Neuro-Oncology (EANO) consensus review on current management and future directions. Neuro-oncology. 22, 1073-1113. doi: 10.1093/neuonc/noa a106

Xiong, Z. G., Zhu, X. M., Chu, X. P., Minami, M., Hey, J., Wei, W. L., et al. (2004). Neuroprotection in ischemia: blocking calcium-permeable acid-sensing ion channels. Cell 118, 687-698. doi: 10.1016/j.cell.2004.08.026

Yu, L., Zhang, G., and Qi, S. (2021). Aggressive treatment in glioblastoma: what determines the survival of patients? J. Neurol. Surg. A Cent. Eur. Neurosurg. 82, 112-117. doi: 10.1055/s-0040-1713172

Conflict of Interest: The authors declare that the research was conducted in the absence of any commercial or financial relationships that could be construed as a potential conflict of interest.

Publisher's Note: All claims expressed in this article are solely those of the authors and do not necessarily represent those of their affiliated organizations, or those of the publisher, the editors and the reviewers. Any product that may be evaluated in this article, or claim that may be made by its manufacturer, is not guaranteed or endorsed by the publisher.

Copyright (C) 2021 Shah, Chu, Cegielski and Chu. This is an open-access article distributed under the terms of the Creative Commons Attribution License (CC BY). The use, distribution or reproduction in other forums is permitted, provided the original author(s) and the copyright owner(s) are credited and that the original publication in this journal is cited, in accordance with accepted academic practice. No use, distribution or reproduction is permitted which does not comply with these terms. 